THE CAUSALITIES OF PANDEMIC- A STUDY ON DAILY NEEDS
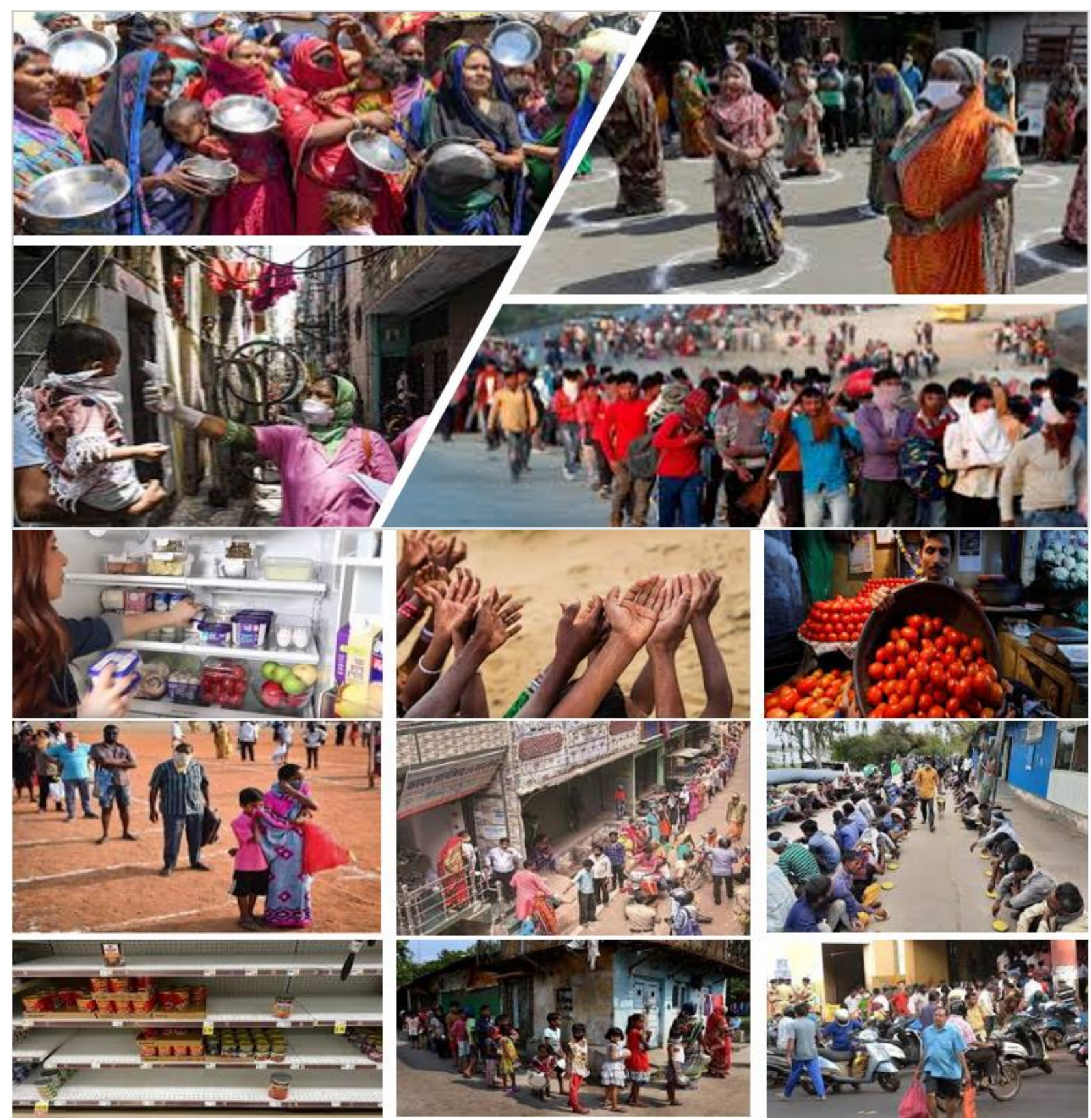

PRESENTED AT

PASKURA BANAMALI COLLEGE(Autonomous)

Somenath Dutta, Shilpa Daw, Prolay Sankar Dey,

Soumya Sarathi Ganguly, Dattatreya Mukherjee,

Somnath De 


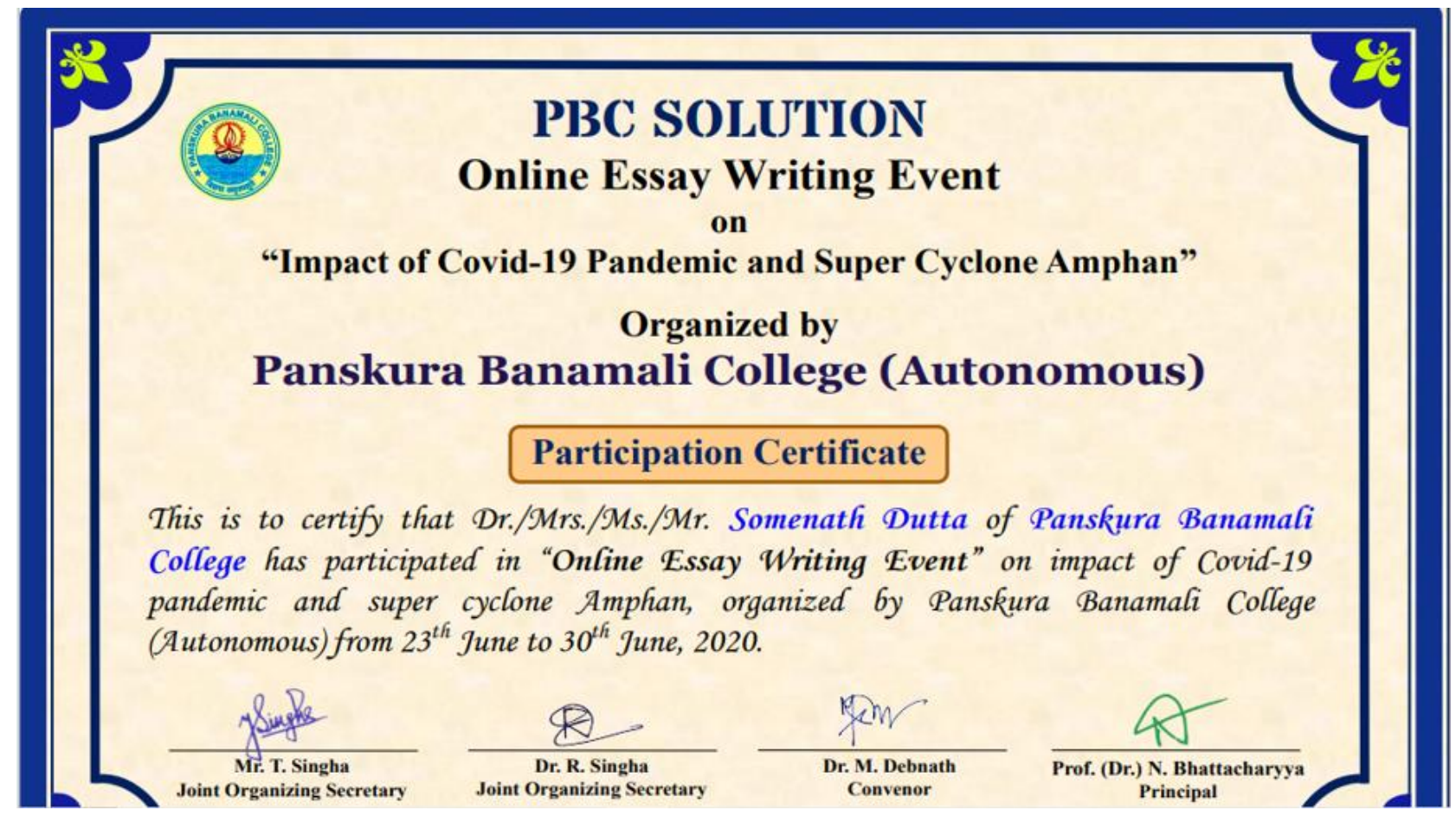

Certificate from Paskura Banamali College

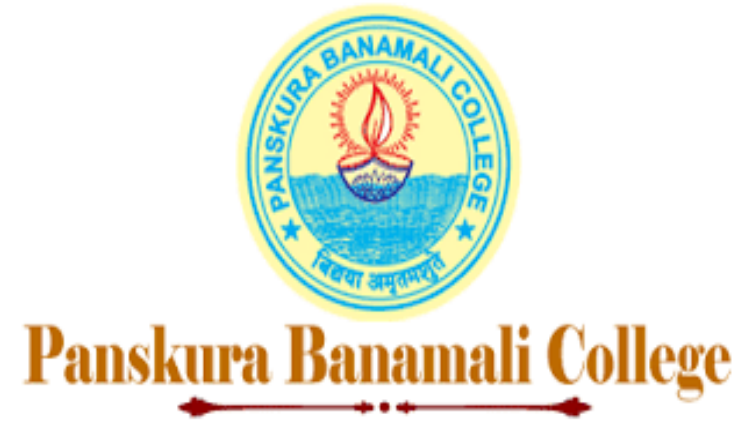

R.S, Kanakpur, Panskura, West

Bengal 721171 


\section{THE CAUSALITY OF PANDEMIC IN 2020}

There are many ongoing debates about the causality of Corona as pandemic, but there should not be a single debate about the globalized effect of this pandemic on our very basic daily life, including all the segments of people from different demographical distribution, throughout the world.

Though in today's world, where most of the segments of life like health, education, medical research and applications, entertainments, employment - are highly connected with highly sensitive globalized character, so the causalities of this pandemic were to be globalized too.

The first and foremost impact of this pandemic was to make the world almost without any movement, just when our life, from each and every ways were to be with more and more speed.

We for the very first time, may be for the first time in the modern literal history, with our latest technologies, incredible merits, exchanging of knowledge got no attacking way at all against this virus. It is pathetic that, we the human being, who just before some days, stepped onto Mars, we got to go the home for our self safety - yes it was the one and only preventive way, that was left before us, to keep our existence .

Very technically, the world got stopped at the very same point, where it was. Except the emergency services - each and every steps were stopped. And we got the basic crystal clear guidelines, from both of our Govt and Medical stuffs that - in place of mass communication we need to adopt and practice the social distancing system to stay far from each and everyone for basic safety . In place of discovering the world, we need to switch our home into world for basic safety. In place of superfast movement, like communication, production - we just need no movement for our basic safety.

In short, the specialists entitled it as "LOCK DOWN ". Life never came to such a stopping point before. So, to be very technically, we faced something, that was beyond our imagination.

The overall experience is almost same everywhere. It is dull. It is regularly monotonous. It is panicked. It is blind everywhere. No one could escape from it.

But still as the world is not based on equalities, same distribution and same vision - so very automatically, the impact of this lockdown due to pandemic - varied from place to place, time to time, and person to person.

As India is one of the largest countries with human resources, natural prosperities, and one of the biggest grounds for the investor, so no doubt that the impact of this lockdown in India is one of yet biggest key factor to the rest of the world. And this impact is not just restricted within any particular area , rather for the whole world it is going to be the leading area and factor - it may be in the case 
community transmission, preventive and curative steps against the pandemic, and no doubt for the economical structure for the "era after corona".

So here I started to take a look about the impact of this lockdown on the life of common Indians. Many more sectors, category of people, and aspects are yet to be added.

In my first attempt, I tried to make a survey report by Google Doc. just on 100 persons including various grounds to have the very basic line, so that in future we may get more people with different conditions to judge the overall impact in depth.

Before I am going to present the ongoing situations to get basic trend, I am confirming it again, that just an online survey within 100 people is never enough to get the country's condition. It is just an effort to have the basic trend and we confirm to add more and more people and more and more sectors, so that in future, we may get a distinct concept about the ongoing and upcoming changes, those are coming to our daily life and life-based concept and activities.

\section{Here I focus on some basic areas ----}

1) Food Stock - In time of lock down, $79 \%$ people were with their normal food stock, $10 \%$ people were with low food stock and only $7 \%$ people were with high level of normal food stock. Here the term "NORMAL FOOD STOCK" - is very conflicting , as distribution is a big factor in India.

YOUR NORMAL STOCK OF FOOD WAS

100 responses

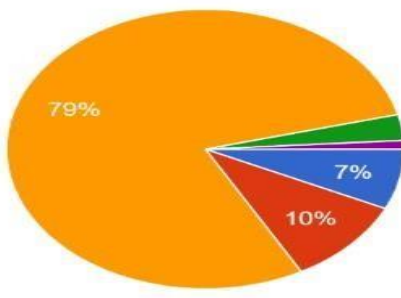

$$
\begin{aligned}
& \text { High } \\
& \text { Low } \\
& \text { Normal } \\
& \text { Nothing } \\
& \text { Very Few }
\end{aligned}
$$

2) Regular Medicine - Just $8 \%$ people had a rich stock of regular medicines, on the contrary $15 \%$ people had no basic stock, and $14 \%$ had low stock and $63 \%$ had normal stock as per theirneed. Almost $29 \%$ people had to suffer from the need of basic regular medicines.

YOUR NORMAL STOCK OF REGULAR MEDICINES WAS

100 responses
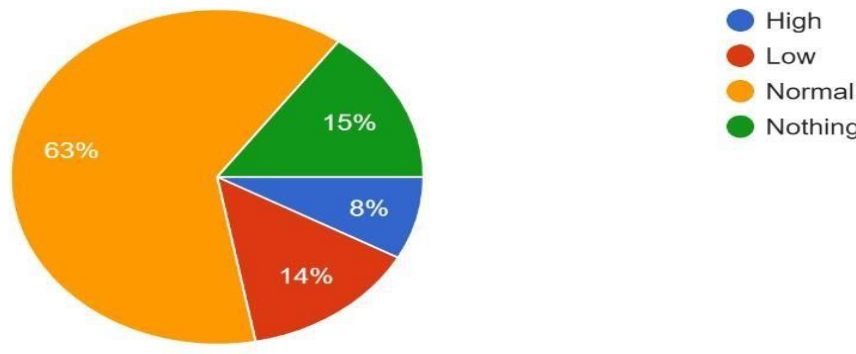
3) Crisis medicine- It is pathetic to get $7 \%$ people to avail crisis period medicines, where $30 \%$ people had just nothing , $40 \%$ got normal and $23 \%$ got at the lowlevel.

YOUR NORMAL STOCK OF CRISIS MEDICINE WAS

100 responses

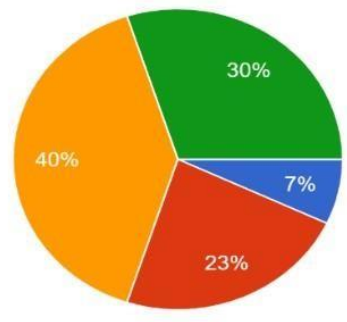

4) Pathological test - When all kinds of medical test could be a big factor , then $33 \%$ people got not even simple pathological test , $29 \%$ people managed somehow at low level and just $36 \%$ people got them at normal level.

YOUR NORMAL STOCK OF PATHOLOGICAL TESTS WAS

100 responses

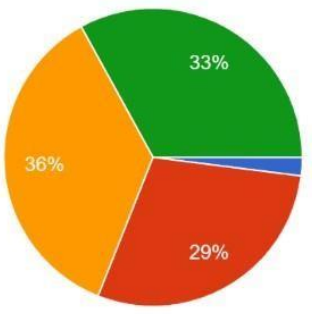

5) Delivery report of medical test - Here just 35\% people got the service as normal , but 39\% got nothing and $24 \%$ were served at poorlevel.

YOUR NORMAL STOCK OF REPORT DELIVERY WAS

100 responses
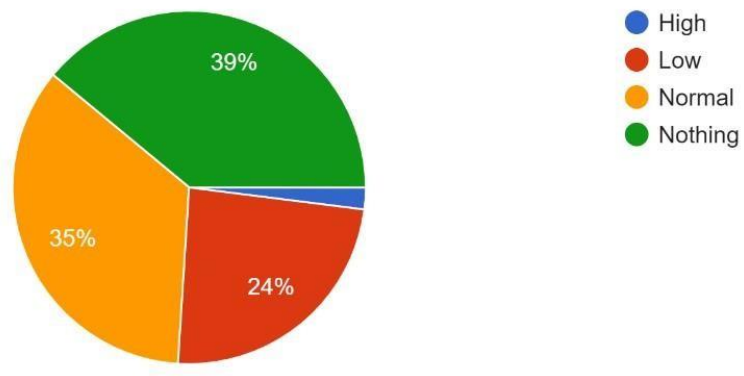
6) Stock of Ration - 62\% people were given normal service and $17 \%$ were with high level service, but $10 \%$ people got nothing and $11 \%$ were served at lowlevel.

YOUR NORMAL STOCK OF RATION SYSTEM WAS

100 responses

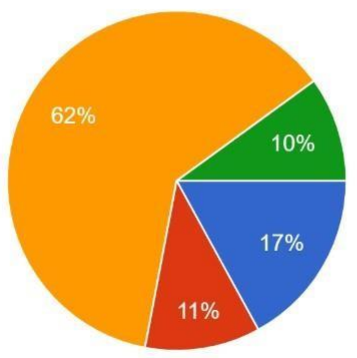

High

Low

Normal

Nothing

7) Food quality of Ration- As per $65 \%$, it was normal, but to $10 \%$ and $11 \%$ people it was nothing or low and as per $17 \%$ it was of highquality.

YOUR NORMAL STOCK OF RATIONED FOOD QUALITY WAS

100 responses

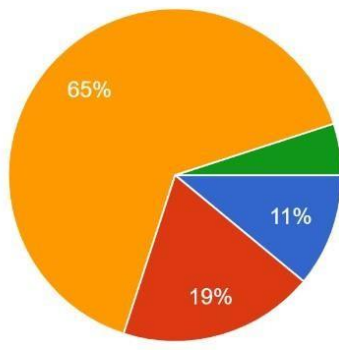

$$
\begin{aligned}
& \text { High } \\
& \text { Low } \\
& \text { Normal } \\
& \text { Nothing }
\end{aligned}
$$

8) Policing System- As per $50 \%$, it was normal, but to $23 \%$ and $11 \%$ people it was nothing or low and as per $16 \%$ it was of high level.

YOUR NORMAL STOCK OF POLICING SYSTEM WAS

100 responses

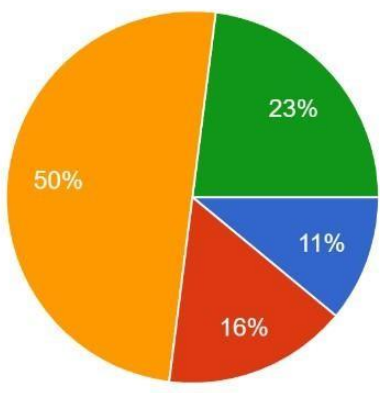


9) Social Awareness- As per $42 \%$, it was normal, but to $3 \%$ and $9 \%$ people it was nothing orlow and as per $46 \%$ it was of high rated.

YOUR NORMAL STOCK OF SOCIAL AWARENESS WAS

100 responses
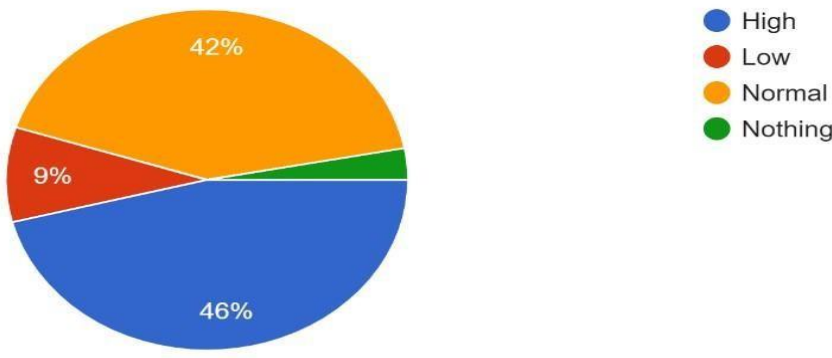

10) Social Relationship- As per $44 \%$, it was normal, but to $6 \%$ and $39 \%$ people it was nothing or low and as per $11 \%$ it was of high level.

YOUR NORMAL STOCK OF SOCIAL RELATIONSHIPS WAS

100 responses

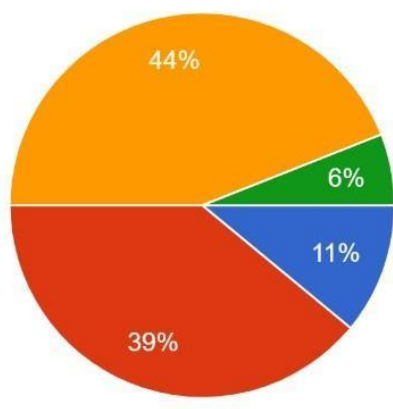

11) Personal Relationship- As per $62 \%$, it was normal, but to $6 \%$ and $21 \%$ people itwas nothing or low and as per $11 \%$ it was of highlevel.

YOUR NORMAL STOCK OF PERSONAL RELATIONSHIPS

100 responses
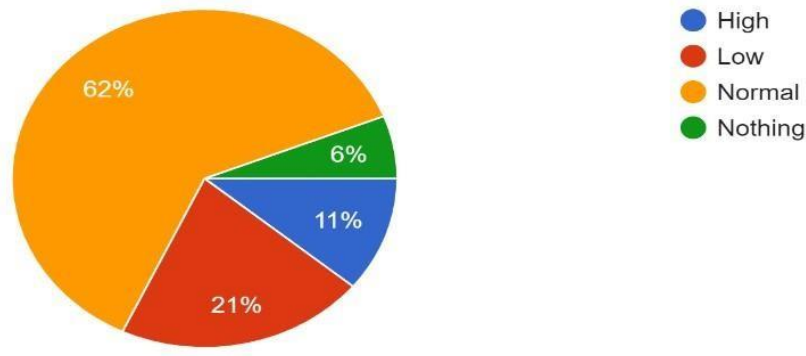
12) Family Relationship-As per $57 \%$, it was normal, but to $2 \%$ and $10 \%$ people it was nothing or low and as per $31 \%$ it was of high level

YOUR NORMAL STOCK OF FAMILY RELATIONSHIPS WAS

100 responses
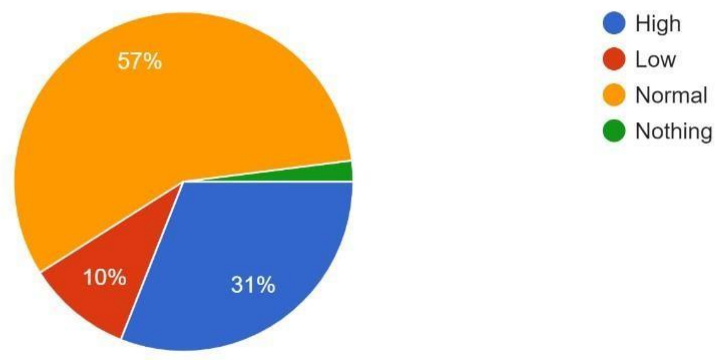

13) Misunderstanding Relationship- As per $41 \%$, it was normal, but to $14 \%$ and $25 \%$ peopleitwas nothing or low and as per $20 \%$ it was of high level

YOUR NORMAL STOCK OF MISUNDERSTANDING IN RELATIONSHIPS

100 responses
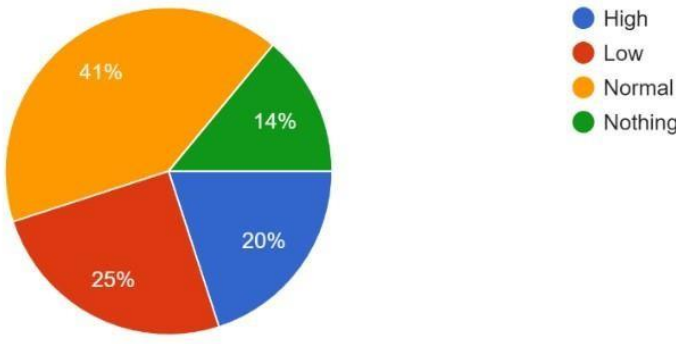

14) Psychological Stress- As per $32 \%$, it was normal, but to $20 \%$ and $22 \%$ people it was nothing or low and as per $26 \%$ it was of highlevel

YOUR OVERALL EXPERIENCE WAS ON ANY KIND OF PSYCHOLOGICAL STRESS

100 responses
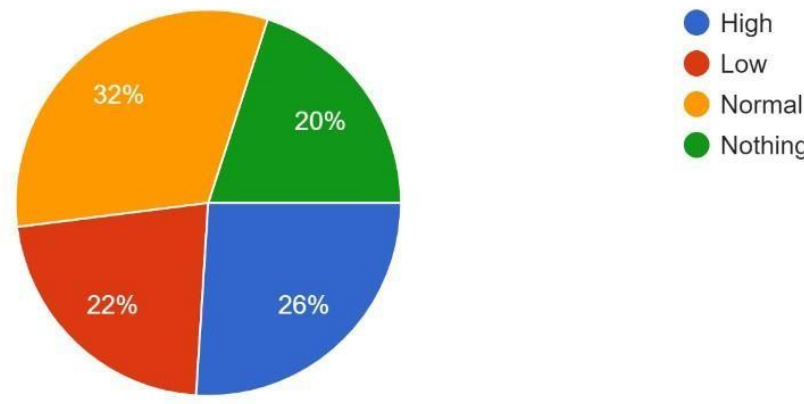
15) Psychological Stress due to Financial Depression- As per 33\%, it was normal, but to $19 \%$ and $23 \%$ people it was nothing or low and as per $25 \%$ it was of high level.

YOUR OVERALL EXPERIENCE WAS ON ANY KIND OF PSYCHOLOGICAL STRESS, DUE TO FINANCIAL DEPRESSION

100 responses

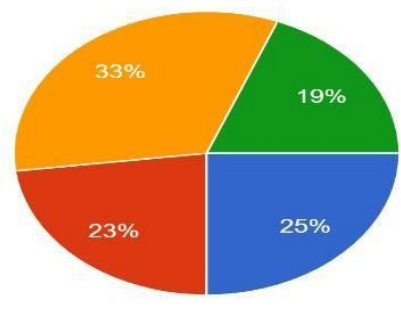

$$
\begin{aligned}
& \text { High } \\
& \text { Low } \\
& \text { Normal } \\
& \text { Nothing }
\end{aligned}
$$

16) Psychological Stress due to anxiety related to Profession - As per $35 \%$, it was normal, but to $19 \%$ and $15 \%$ people it was nothing or low and as per $31 \%$ it was of highlevel.

YOUR OVERALL EXPERIENCE WAS ON ANY KIND OF PSYCHOLOGICAL STRESS DUE TO ANXIETY RELATED TO PROFESSION

100 responses

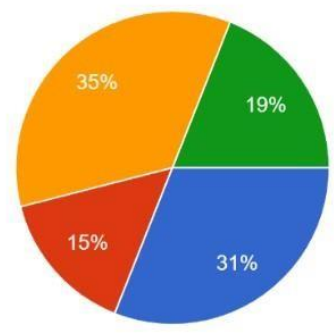

$$
\begin{aligned}
& \text { High } \\
& \text { Low } \\
& \text { Normal } \\
& \text { Nothing }
\end{aligned}
$$

17) Psychological Stress due to Conjugal Relationship-As per $45 \%$, it was normal, but to $30 \%$ and $13 \%$ people it was nothing or low and as per $12 \%$ it was of highlevel.

YOUR OVERALL EXPERIENCE WAS ON ANY KIND OF PSYCHOLOGICAL STRESS DUE TO CONJUGAL RELATIONSHIP

100 responses
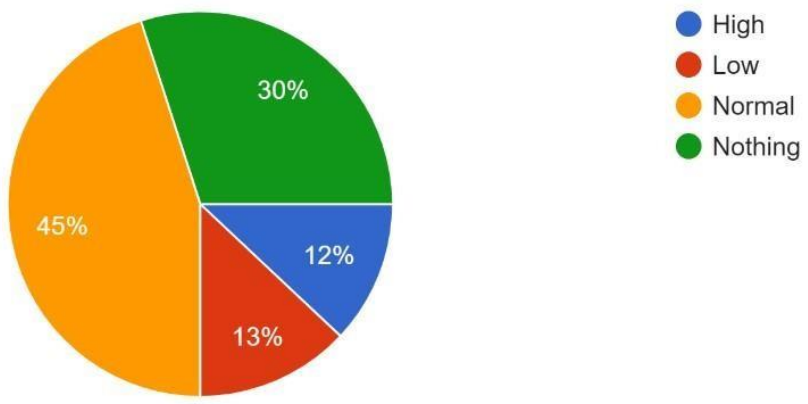
18) Psychological Stress due to sudden change in lifestyle of Children-As per $42 \%$, it was normal, but to $21 \%$ and $14 \%$ people it was nothing or low and as per $23 \%$ it was of high level.

YOUR OVERALL EXPERIENCE WAS ON ANY KIND OF PSYCHOLOGICAL STRESS DUE TO SUDDEN CHANGE IN LIFESTYLE OF CHILDREN

100 responses
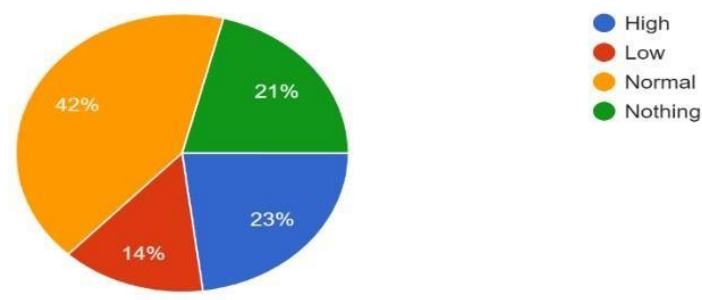

19) Psychological Stress due to sudden change in lifestyle of Elderly People- As per $41 \%$, it was normal, but to $14 \%$ and $16 \%$ people it was nothing or low and as per $29 \%$ it was of highlevel.

YOUR OVERALL EXPERIENCE WAS ON ANY KIND OF PSYCHOLOGICAL STRESS DUE TO SUDDEN CHANGE OF LIFE STYLE OF ELDERLY PEOPLE

100 responses
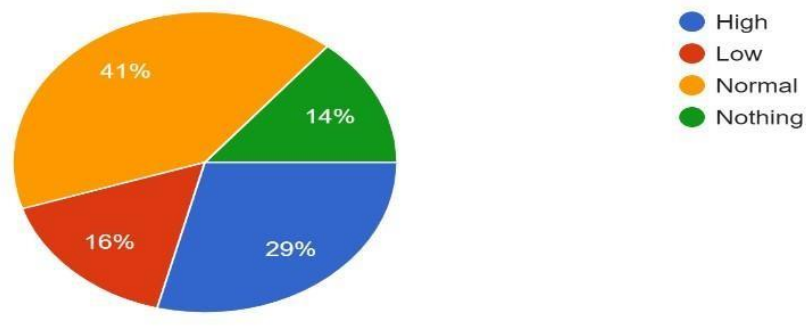

20) Psychological Stress Socio Financial status- As per $41 \%$, it was normal, but to $17 \%$ and $19 \%$ people it was nothing or low and as per $23 \%$ it was of highlevel.

YOUR OVERALL EXPERIENCE WAS ON ANY KIND OF PSYCHOLOGICAL STRESS SOCIO

FINANCIAL STATUS

100 responses
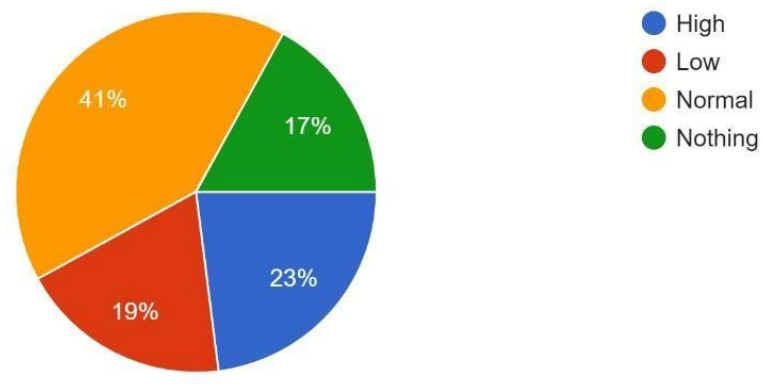
21) Psychological Stress due to Entertainment Level- As per $41 \%$, it was normal, but to $19 \%$ and $20 \%$ people it was nothing or low and as per $20 \%$ it was of highlevel.

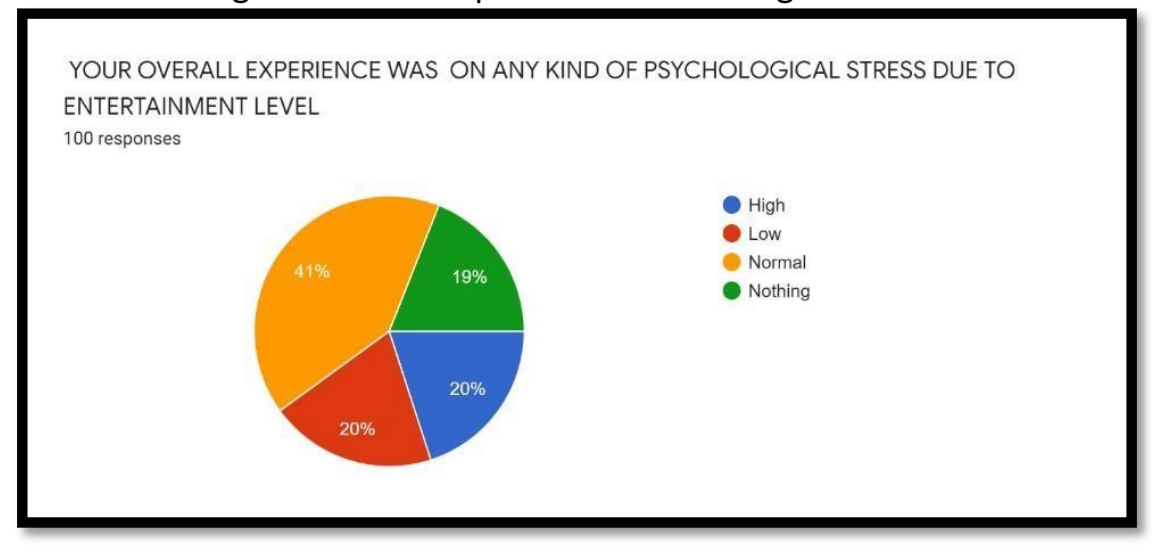

22) Psychological Stress due to Life Style Changing -As per $38 \%$, it was normal, but to $14 \%$ and $20 \%$ people it was nothing or low and as per $28 \%$ it was of highlevel.

YOUR OVERALL EXPERIENCE WAS ON ANY KIND OF PSYCHOLOGICAL STRESS DUE TO LIFE STYLE CHANGING

100 responses

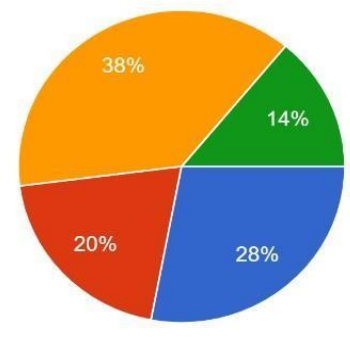

High

Low

Normal

Nothing

23) Psychological Stress due to change in Addiction Level - As per $34 \%$, it was normal, but to $30 \%$ and $22 \%$ people it was nothing or low and as per $14 \%$ it was of highlevel.

YOUR OVERALL EXPERIENCE WAS ON ANY KIND OF PSYCHOLOGICAL STRESS DUE TO CHANGE IN ADDICTION LEVEL

100 responses
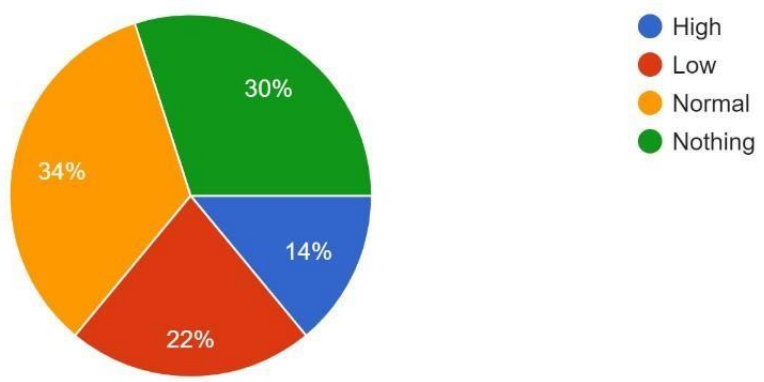


\section{Conclusion: -}

It is clear from the ongoing situations throughout the world, that it is not so easy now to conclude the causalities of this pandemic. No doubt that most of the scholars including medical researchers, doctors, environmental researchers, people working with politics, economy, sociology and so many grounds are now at a common point - and that point is of change. But none is sure about the ultimate change that is already is faced by all of us. The first and foremost point is that we are yet to have a common solution point. It is not possible too now as we just entered into the situation. And through such a little effort it is not possible to mark any area to be focused or not. It is just a trend checking survey and I got some areas like employment, food chain, social attachments, and habitations to be the first level of change. But the way the total situation is being changed so fast, it will be better observed. And these times I surveyed on 100 people from different demography, but this is not enough. As the situation moves on and I will work on more and more people, hope we may get the vibes of upcoming changes.

Presented: June 2020

Posted in OSF: March 2021 